\title{
Tool for Assessing Green Initiatives in Library or Green Initiatives in Library: Formulating an Assessment Tool
}

\author{
Khairul Nazli Razali ${ }^{1 *}$, Farrah Zuhaira Ismail ${ }^{1}$ \\ ${ }^{1}$ Faculty of Architecture, Planning and Surveying, \\ Universiti Teknologi MARA (UiTM), 40450, Shah Alam, Selangor, MALAYSIA \\ *Corresponding Author
}

DOI: https://doi.org/10.30880/jstard.2021.03.02.007

Received 15 November 2021; Accepted 20 October 2021; Available online 15 December 2021

\begin{abstract}
Amid environmental crisis, the role of built environment sector becomes even more vital as it has a potential to make a significant contribution in reducing greenhouse gas emissions and energy consumption. Library specifically, plays a crucial role in supporting the mission of promoting environmental practice. However, limited rating system explicitly for library's green initiatives makes it challenging for library to implement these initiatives due to lack of proper guidelines. Hence, this study was conducted to examine existing checklists measuring green initiatives in library and to formulate a checklist for assessing green initiatives in library's facilities. A systematic review was conducted to establish an assessment checklist, in which three existing checklists related to green initiatives in library were compared and referred to. The assessment checklist developed in this study identifies 107 initiatives related to facilities can be implemented by existing libraries in Malaysia. The result of this study serves as a basis for libraries in Malaysia to environmentally improve its facilities.
\end{abstract}

Keywords: green library; green initiatives; assessment tools

\section{Introduction}

Qutab et al. (2016) emphasized that due to global climate change, it is crucial for built environment to take action on green or sustainable initiatives [26]. According to Binks et al. (2014), the sector of built-environment has a potential to make significant contribution in reducing greenhouse gas emissions and energy consumption [3]. As stated by Gupta et al. (2018), since library is a service-oriented institution, it can engage in ecological revolution through the adoption of green library's concept [6]. Babare and Aute (2018) supported this by stating library can play a role to motivate individuals and community to work towards protecting the environment [2]. Accordingly, Cardoso and Machado (2015) suggested that public library in particularly, should be the first institution to incorporate sustainable practices and be the models of green cultural due to the fact that it is supported by the government [5].

Therefore, in order to support the sustainable development, International Federation of Library Association has introduced the IFLA Green Library Award in 2016 (IFLA, 2016) [10]. However, according to Hauke (2015) there are only few national library associations that support green library movement [8]. Nonetheless, ever since its introduction in 2016, the IFLA Green Library Award has been receiving more than 30 applications from all around the world every year (Hauke, 2019) [9]. This indicates the awareness on green library does exist globally. Meher and Parabhoi (2017) supported this by stating that green library is a new concept and is gaining interest among library professional [17]. However, Hauke (2015) argued developing and measuring green library can be challenging due to the absence of specified certification and rating system for green library [8].

It is crucial for library to include in its consideration initiatives to reduce its environmental impact. As claimed by Munawaroh and Bestari (2018), extensive use of paper is not the only concern for library, its operations, buildings, facilities, collections, and users' behaviour also have an influence on global warming [20]. Similarly, Wong (2016) mentioned due to library's long service hours added with its constant need of air-conditioning, reducing the electricity consumption of library is challenging [30]. The high consumption of energy in library is mainly due to the fact that energy is utilized for lighting, heating, air-conditioning, and ventilation (Hauke et al., 2013) [7]. Morris (2007) added, 
all these services influenced the condition of library's indoor environment which in turn influence the lifespan of book (as cited in McElrath and Sutherland, 2015) [16]. As agreed by Malode (2014), for preservation purpose, books need to be kept away from sunlight, moisture, and temperature change [15]. Thus, library consumes high amount of energy in order to maintain its indoor environment for the purpose of preserving its collection. Hence, to manage the issue of high energy consumption it is crucial for libraries to have green initiatives implemented. McElrath and Sutherland (2015) acknowledged this by suggesting that libraries shall apply environmentally friendly policies and practices since it consumes large amount of energy [16]. Additionally, due to these issues, library professionals are making an effort to establish such a kind of library that can be regarded as energy efficient, environmentally friendly, and promotes the minimization of electricity consumption (Gupta et al., 2018) [6].

In Malaysia however, with a total of 13,463 libraries as reported in the Annual Report of National Library of Malaysia (2018) [21], the issue on formation of first green library in Malaysia only arose in 2012. As mentioned in Tender for Sabah's First Green Library to be called soon (2012), Sabah would be the first state to have green library in the country [28]. Thus, the objectives of this study are to analyse existing checklists assessing green initiatives' implementation in library and later formulate a checklist assessing the implementation of green initiatives in library's facilities with focus given on existing library under operation situated at Malaysia.

\subsection{Definition of Green Initiatives}

In accordance to Binks et al. (2014), the word "green" is synonymous with the term "sustainability" [3]. Sustainability is defined as a development which meet present's needs without affecting the ability of future generation's needs to be met (World Commission on Environment and Development, 1987) [31]. However, according to Meher and Parabhoi (2017), prior of recognizing sustainable development, green initiatives play significant role in making environment a sustainable one [17]. Yusof and Jamaludin (2015) identified several synonyms for green initiatives which include environmentally friendly practices, green approaches, best practices, green environmental attributes, environmental practices, and sustainable practices [32].

\subsection{Definition of Green Library}

Amin and Shoid (2017) identified the following aspects described the quality of a library: (1) Environment, (2) Collection, (3) Facilities, (4) Services, and (5) Staff's ability [1]. Amin and Shoid (2017) added, library facilities are the most important element as it provides convenience to users and the main contributor for users' satisfaction [1].

As mentioned in Online Dictionary of Library and Information Science (n.d.), sustainable library is a library which is designed to minimize negative impact on the natural environment while maximizing indoor environmental quality by means of careful site selection, use of natural construction materials and biodegradable products, conservation of resources, and responsible waste disposal [27]. IFLA (2019) stated that green library is a library that demonstrates the social role and responsibility of libraries as leaders in environmental sustainability by focusing on related services, activities, events, literature and projects [11].

Other than the library building itself, green library refers to the library's services, activities, events, literature, and projects that relate to sustainability which follows the United Nations Agenda 2030 (Hauke, 2019) [9]. More (2016) supported green technology practices in library are more than constructing a green building, it involves greening library's facilities, supporting green library services, and promoting environmentally sustainable activities within library [18]. As highlighted by Munawaroh and Bestari (2018), green library does not merely refer to its building and physical design, it also includes its collection, operations, along with its librarians and users' behaviours [20]. Thus, it can be concluded that green library does not necessarily refers to library's building which is green certified, but it refers to library's operation which minimise its impact on natural environment. As cited by Wong (2016), Aulisio (2013) supports this by mentioning the term "green library" does not only refer to library's building that is green certified but also include library that encourages sustainability [30]. Additionally, Patil (2018) stated the innovation of green library can be achieved through constructing green library building, greening existing facilities of library, arranging green library services, and encouraging environmentally sustainable practices within library [25]. Burn (2014) suggested it is crucial for a library to make its green features visible in order to ensure the environmental message is delivered to its audiences [4].

In comparing sustainable library with green library, Meher and Parabhoi (2017) suggested that sustainable library is similar with green library, which refers to modern library with minimal consumption of electricity and maximum use of renewable sources [17]. Malode (2014) supported that sustainable library is also referred as green library, which indicates a library built with environmental concerns [15]. Nikam (2017) also agreed that sustainable library can be referred as green library. Hence, it can be concluded that the term sustainable library is synonym with green library [23]. 


\subsection{Importance of Greening the Library}

Patil (2018) supported it is important for library to go green in order to control pollution and global warming, develop awareness on environmental issue, examine major green library initiatives, and enhance environmental consciousness [25]. Cardoso and Machado (2015) through their study conducted in a library situated in Brazil, Biblioteca Parque do Estado do Rio de Janeiro (BPERJ), found through the implementation of green initiatives in the library, electricity and water consumption of BPERJ is able to be reduced by $28 \%$ and $45 \%$ respectively [5]. In addition, through the implementation of green practices and principles in library, community's awareness with regards to benefits obtained from implementing these practices and how these practices can be further implemented in home environment can be raised (Binks et al., 2014) [3].

\subsection{Existing Tools for Assessing Green Initiatives in Library}

As mentioned by Hauke (2015), specified certification and rating system for green library are unavailable [8]. Therefore, assessment checklist design for assessing the implementation of green initiatives in library is also found to be limited. Through this study, three assessment checklists for assessing green initiatives implementation in library are found. These checklists are developed by Mulford and Himmel (2010), Werner (2013), and Noh and Ahn (2018).

\section{Research Methodology}

\subsection{Systematic Review}

In this study, a systematic review was conducted in order to examine existing checklists measuring green initiatives in library followed by developing this study's own checklist that focuses on library's facilities, applicable on existing library that is under operation, and practicable in Malaysia.

Systematic review is defined as a research study where numbers of previous reports are investigated in order to identify key ideas and themes (Leedy and Ormrod, 2015) [13]. Systematic review was carried out in order to formulate a checklist assessing green initiatives in library. Based on Leedy and Ormrod (2015), following are steps adopted in developing the assessment checklist [13]:

- Evaluating each existing checklist

- Coding the contents of checklist based on themes

- Performing the meta-analysis

Based on these steps, three phases were involved in carrying out the systematic review in this study. These phases include: (1) Analysing green initiatives that relate to facilities, applicable during post-construction stage, and practicable in Malaysia, (2) Analysing green initiatives based on Authors, and (3) Coding the green initiatives based on themes.

\subsection{Collecting Existing Checklists}

Existing checklists related to assessing green initiatives in library were collected. Google scholar was used as the search engine to search for published articles with assessment checklist related to green initiatives in library. Articles with the keyword "green library" in the title was first searched which led to 658 articles found. Next, the date of published articles was specified between the year 2010 to 2019 which resulted in the numbers of articles to decrease to 314. Amongst those 314 articles, only three (3) articles were found to have tools related to assessing green initiatives in library. One of those articles is a book written by Mulford and Himmel (2010) and two of those articles are journals written by Werner (2013) and Noh and Ahn (2018).

Hence, three established assessment checklists by Mulford and Himmel (2010), Werner (2013), and Noh and Ahn (2018) were systematically reviewed in establishing the assessment checklist. As suggested by Hauke (2015). certification and rating systems that focus directly on green library is not available [8]. This explains the limited numbers of established tools focusing on green initiatives in library. Both Mulford and Himmel (2010) and Werner (2013) claimed that checklists formed cannot be considered as an exhaustive checklist [19,29]. However, it still can aid in designing a greener library. Moreover, Hauke (2015) suggested that checklist formed by Werner (2013) is considered as a suitable checklist to be used internationally in assessing green initiatives within library [8]. In addition, Noh and Ahn (2018) developed evaluation indicators that focus directly on green library. Hence, those evaluation indicators were also included in the systematic review.

\subsection{Reviewing Existing Checklists}

This study focuses on initiatives that matched these three criteria: (1) Related to facilities, (2) Applicable during post-construction stage, and (3) Practicable in Malaysia. Hence, in forming the assessment checklist, only those initiatives that match these three criteria were included. After analysing the initiatives listed in three existing checklists 
developed by Mulford and Himmel (2010), Werner (2013), and Noh and Ahn (2018), referring to the three criteria specified, those initiatives that do not match the criteria were excluded.

Second phase of developing the checklist for this study involves summarising three of the established checklists developed by Mulford and Himmel (2010), Werner (2013), and Noh and Ahn (2018). This phase was carried out to identify the similarities and differences between these three checklists, along with avoiding similar initiatives to be repeated in the checklist formed for this study.

Third and final phase of developing the assessment checklist involves establishing themes for the initiatives included in the checklist formed. In this phase, initiatives identified during the second phase were divided into themes by carrying out an inductive coding. Similar method was practiced by Noh and Ahn (2018) in their study to develop checklist for assessing green initiatives in library in which the green initiatives were grouped based on similar characteristics.

\subsection{Limitation}

This study reviews previous literatures by Mulford and Himmel (2010), Werner (2013), and Noh and Ahn (2018) which respectively mention 46, 163, and 126 green initiatives in their studies. However, in formulating its own checklist through systematic review, this study only includes those initiatives that match the criteria listed below:

- Applicable in Malaysia

- Practicable in library under the operation and maintenance stage of building life cycle

- Relate to library's facilities

\section{Findings and Discussion}

\subsection{Evaluation of Initiatives from Existing Checklist with Criteria Specified}

Table 1 shows the summary of initiatives that match with criteria specified in this study in accordance to each existing checklist.

Table 1 - Summary of initiatives matched with criteria specified

\begin{tabular}{ccccc}
\hline No & Checklist based on author(s) & $\begin{array}{c}\text { Total numbers } \\
\text { of initiatives } \\
\text { mentioned }\end{array}$ & $\begin{array}{c}\text { Numbers of } \\
\text { initiatives match } \\
\text { with the criteria }\end{array}$ & $\begin{array}{c}\text { Percentage of } \\
\text { initiatives match } \\
\text { with the criteria }\end{array}$ \\
\hline 1. & Noh and Ahn (2018) & 126 & 75 & $60 \%$ \\
2. & Werner (2013) & 163 & 72 & $44 \%$ \\
3. & Mulford and Himmel (2010) & 46 & 39 & $85 \%$ \\
\hline
\end{tabular}

In achieving the first objective which is to examine existing checklists measuring green initiatives in library, systematic review with three phases as stated in $\mathbf{2 . 1}$ is adopted. For the first phase of the systematic review, three existing checklists are analysed based on its initiatives in order to exclude those initiatives that do not match the three criteria specified. Those three criteria are initiatives: (1) Relate to facilities, (2) Applicable during post-construction, and (3) Practicable in Malaysia.

Checklist developed by Noh and Ahn (2018) has the most initiatives that matched the three criteria specified upon with 75 initiatives in total, followed by checklist developed by Werner (2013) with 72 initiatives, and Mulford and Himmel's (2010) with 39 initiatives. With 39 initiatives, checklist by Mulford and Himmel (2010) has the least initiatives that matched the criteria due to lower numbers of total initiatives as compared to the other two checklists. Mulford and Himmel (2010) categorised the checklist developed as a preliminary green assessment checklist focuses on measuring the current condition of an existing library. Therefore, in term of percentage, $85 \%$ of initiatives mentioned in checklist developed by Mulford and Himmel (2010) matched with criteria specified of being related to facilities, applicable during post-construction stage, and practicable in Malaysia.

Additionally, compared to the other two existing checklists, checklist by Mulford and Himmel (2010) has the highest percentage in term of initiatives that matched the criteria specified. With $44 \%$, checklist developed by Werner (2013) has the lowest numbers of initiatives matching with criteria specified. The reason is, other than initiatives applicable during operation stage of library, the checklist includes initiatives can be taken during planning and construction stage of library. Therefore, 42 of initiatives in the checklist formed by Werner (2013), which is equal to $26 \%$ are related to initiatives that is only applicable during the design and construction stage of the library. 


\subsection{Evaluation of Green Initiatives in Library's Facilities Based on Authors}

In achieving the first of objective of this study, second phase of the systematic review involved summarising green initiatives stated in three existing checklists by Noh and Ahn (2018), Werner (2013), and Mulford and Himmel (2010). In addition, the frequency of these initiatives being mentioned in those existing checklists were also evaluated and shown in table below.

Table 2 - Summary of checklist for assessing green initiatives at library based on authors

\begin{tabular}{|c|c|c|c|c|}
\hline No & Initiatives & $\begin{array}{c}\text { Noh \& } \\
\text { Ahn } \\
(2018)\end{array}$ & $\begin{array}{l}\text { Werner } \\
(2013)\end{array}$ & $\begin{array}{c}\text { Mulford \& } \\
\text { Himmel } \\
(2010)\end{array}$ \\
\hline 1 & Utilized software solutions to optimize energy & & $\checkmark$ & \\
\hline 2 & $\begin{array}{l}\text { Utilized energy-saving electrical appliance and } \\
\text { energy-efficient hot water production for kitchen }\end{array}$ & & $\checkmark$ & \\
\hline 3 & Provided solar energy for cooling or heating & $\checkmark$ & & \\
\hline 4 & Utilized hydrogen fuel cell for electricity & $\checkmark$ & & $\checkmark$ \\
\hline 5 & Utilized bio-energy for electricity & $\checkmark$ & & $\checkmark$ \\
\hline 6 & Utilized solar energy generation for electricity & $\checkmark$ & $\checkmark$ & $\checkmark$ \\
\hline 7 & Conducted an energy audit of the facility & & & $\checkmark$ \\
\hline 8 & Established agreed target for energy saving & & $\checkmark$ & \\
\hline 9 & Made energy-use visible & & $\checkmark$ & \\
\hline 10 & Tracked energy usage & & & $\checkmark$ \\
\hline 11 & Avoided major use of air-conditioning & & $\checkmark$ & \\
\hline 12 & Used influx and release of outside air for air- & $\checkmark$ & & \\
\hline 13 & Provided occupant-controlled lighting & & $\checkmark$ & $\checkmark$ \\
\hline 14 & Used steel halide lamp with low voltage & $\checkmark$ & & \\
\hline 15 & Installed lighting controlled by sensors & $\checkmark$ & $\checkmark$ & \\
\hline 16 & Used fluorescent light with high energy efficiency & $\checkmark$ & & \\
\hline 17 & Installed step switching and dimmer switches & & $\checkmark$ & \\
\hline 18 & Installed efficient lighting control panels & & $\checkmark$ & \\
\hline 19 & Used thin clients instead of PCs & & $\checkmark$ & \\
\hline 20 & Used high efficient printer & $\checkmark$ & $\checkmark$ & \\
\hline 21 & $\begin{array}{l}\text { Recovered waste heat from refrigeration and air- } \\
\text { conditioning systems to heat water }\end{array}$ & & $\checkmark$ & \\
\hline 22 & Installed electric flash heater & $\checkmark$ & & \\
\hline 23 & Tracked water usage & & & $\checkmark$ \\
\hline 24 & Conducted water usage audit & & & $\checkmark$ \\
\hline 25 & Used water-efficient fixtures & & $\checkmark$ & $\checkmark$ \\
\hline 26 & Incorporated rainwater harvesting & $\checkmark$ & $\checkmark$ & $\checkmark$ \\
\hline 27 & Installed drain to collect rainwater & & & $\checkmark$ \\
\hline 28 & Installed facilities utilizing rainwater & $\checkmark$ & & \\
\hline 29 & Utilized rainwater for irrigation & $\checkmark$ & & \\
\hline 30 & Installed automatic irrigation facilities & $\checkmark$ & & \\
\hline 31 & Incorporated greywater system & $\checkmark$ & $\checkmark$ & $\checkmark$ \\
\hline 32 & Installed sewage purification system & $\checkmark$ & & \\
\hline 33 & Conducted solid-waste audit of the facility & & & $\checkmark$ \\
\hline 34 & Reused items that have useful life & & & $\checkmark$ \\
\hline 35 & Installed collection box for used batteries & $\checkmark$ & & \\
\hline 36 & Installed storage facilities for recycled waste & $\checkmark$ & & \\
\hline 37 & Recycled waste books & $\checkmark$ & $\checkmark$ & \\
\hline 38 & Recycled printer cartridges & & $\checkmark$ & \\
\hline 39 & Recycled and donated e-waste & $\checkmark$ & $\checkmark$ & \\
\hline 40 & Recycled containers and packaging & $\checkmark$ & $\checkmark$ & \\
\hline 41 & Recycled lightbulb & $\checkmark$ & $\checkmark$ & \\
\hline 42 & Recycled library furniture & $\checkmark$ & & \\
\hline 43 & Provided alternatives to plastic bags & & $\checkmark$ & $\checkmark$ \\
\hline 44 & Used biodegradable or real plates and utensils & & & $\checkmark$ \\
\hline 45 & Composted spent vegetation & & & $\checkmark$ \\
\hline
\end{tabular}




\begin{tabular}{|c|c|c|c|c|}
\hline 46 & $\begin{array}{l}\text { Provided manual and guidelines for effective } \\
\text { operation and maintenance of equipment and facility }\end{array}$ & $\checkmark$ & & \\
\hline 47 & Performed regular maintenance on all building & $\checkmark$ & & $\checkmark$ \\
\hline 48 & Utilized building control system & & & $\checkmark$ \\
\hline 49 & Performed remote management & & $\checkmark$ & \\
\hline 50 & Complied to ISO 14000 & & $\checkmark$ & \\
\hline 51 & Used materials with low diffusion rate of VOC & $\checkmark$ & & \\
\hline 52 & Installed indoor air purification system & $\checkmark$ & & \\
\hline 53 & Provided switchable sockets for PCs and printers & & $\checkmark$ & \\
\hline 54 & Installed acoustic baffles & & $\checkmark$ & \\
\hline 55 & Installed revolving doors & & $\checkmark$ & \\
\hline 56 & Utilized certified eco-labelling products & $\checkmark$ & $\checkmark$ & \\
\hline 57 & Installed heat recovery ventilation system in ceiling & $\checkmark$ & & \\
\hline 58 & Used renewable, reusable or recyclable fixtures and & $\checkmark$ & $\checkmark$ & \\
\hline 59 & Reused shelved of existing buildings & $\checkmark$ & & $\checkmark$ \\
\hline 60 & Installed blinds at windows & $\checkmark$ & $\checkmark$ & \\
\hline 61 & Installed low-lying windows & $\checkmark$ & $\checkmark$ & \\
\hline 62 & $\begin{array}{l}\text { Installed windows with glazing quality that supports } \\
\text { thermal insulation }\end{array}$ & & $\checkmark$ & \\
\hline 63 & $\begin{array}{l}\text { Utilized computer control system to enable } \\
\text { adjustment of glass windows }\end{array}$ & $\checkmark$ & & \\
\hline 64 & Used facilities to enable influx of sunlight in roof & $\checkmark$ & & \\
\hline 65 & $\begin{array}{l}\text { Utilized facilities made up of translucent materials to } \\
\text { allow light transmission }\end{array}$ & $\checkmark$ & $\checkmark$ & \\
\hline 66 & Used materials obtained from library land site for & $\checkmark$ & & \\
\hline 67 & Installed automatic air-circulation system & $\checkmark$ & & \\
\hline 68 & Purchased fixtures and furnishing locally & & & $\checkmark$ \\
\hline 69 & $\begin{array}{l}\text { Evaluated certification of displaying carbon dioxide } \\
\text { score for used materials }\end{array}$ & $\checkmark$ & & \\
\hline 70 & Used drought-resistant plants & $\checkmark$ & & $\checkmark$ \\
\hline 71 & Linked indoor library with an ecological park & $\checkmark$ & & \\
\hline 72 & Incorporated green roof & $\checkmark$ & $\checkmark$ & \\
\hline 73 & Incorporated green wall & $\checkmark$ & & \\
\hline 74 & Provided green outdoor environment and & $\checkmark$ & $\checkmark$ & \\
\hline 75 & Utilized trees and sunlight & & & $\checkmark$ \\
\hline 76 & Irrigated site landscape & & & $\checkmark$ \\
\hline 77 & $\begin{array}{l}\text { Designed effective space arrangement by } \\
\text { considering user movement flow }\end{array}$ & $\checkmark$ & & \\
\hline 78 & Provided rest space & $\checkmark$ & & \\
\hline 79 & Provided flexible use of library spaces & $\checkmark$ & $\checkmark$ & \\
\hline 80 & $\begin{array}{l}\text { Provided differentiation of climate concept } \\
\text { according to library function }\end{array}$ & & $\checkmark$ & \\
\hline 81 & Divided area types according to ecological values & $\checkmark$ & & \\
\hline 82 & Utilized extensive resource saving compact storage & & $\checkmark$ & \\
\hline 83 & Performed night cooling & & $\checkmark$ & \\
\hline 84 & Ventilated library before opening & $\checkmark$ & & \\
\hline 85 & Provided natural ventilation & & $\checkmark$ & $\checkmark$ \\
\hline 86 & Provided interior space with access to outside views & & & $\checkmark$ \\
\hline 87 & Avoided artificial humidification & & $\checkmark$ & \\
\hline 88 & Provided individual climate control in workspaces & & & $\checkmark$ \\
\hline 89 & Provided interior space with access to daylight & $\checkmark$ & $\checkmark$ & $\checkmark$ \\
\hline 90 & Influx outside air through carbon dioxide monitoring & $\checkmark$ & & \\
\hline 91 & Complied to non-smoking policy & $\checkmark$ & & \\
\hline 92 & Conducted environmental quality audit & & & $\checkmark$ \\
\hline 93 & Re-used air from print or copy rooms and air- & & $\checkmark$ & \\
\hline 94 & Provided bicycle shed & $\checkmark$ & $\checkmark$ & \\
\hline 95 & Established connections to public transport & $\checkmark$ & $\checkmark$ & $\checkmark$ \\
\hline
\end{tabular}




\begin{tabular}{cllc}
96 & Allowed forms to be completed and submitted & & $\checkmark$ \\
\hline 97 & Utilized electronic or digital communication & & $\checkmark$ \\
\hline 98 & Provided alternative commuting options for staff & $\checkmark$ & \\
\hline 99 & $\begin{array}{l}\text { Reduced emission of carbon dioxide in } \\
\text { transportation by using local materials }\end{array}$ & $\checkmark$ & $\checkmark$ \\
\hline 100 & Used eco-friendly cleaning products & $\checkmark$ & $\checkmark$ \\
\hline 101 & Ensured economic usage of cleaning materials & & $\checkmark$ \\
\hline 102 & Isolated chemicals and storage in ventilated room & & \\
\hline 103 & Avoided the use of pesticides and chemical fertilizer & & \\
\hline 104 & Controlled noise during cleaning routines & $\checkmark$ & \\
\hline
\end{tabular}

A total of 104 initiatives were identified. From these 104 green initiatives, only 6 green initiatives are being mentioned in all three existing checklists. These initiatives are: (1) Utilizing solar energy to generate electricity, (2) Incorporating rainwater harvesting, (3) Incorporating greywater system, (4) Enhancing intake of daylight for interior space, (5) Establishing connection to public transport, and (6) Using eco-friendly cleaning products. The fact that numbers of initiatives relate to energy and water are being mentioned in all three of the existing checklists indicates that issue regarding these aspects are highly being taken into consideration in implementing green initiatives in library's facilities. As argued by Jankowska (2010) and supported by Babare and Aute (2018), significant amount of energy and water are being consumed in library's operation [12, 2]. Thus, including these aspects in checklist developed is decisive. As for the initiatives establishing connection to public transport and using eco-friendly cleaning products, a study by Newton and Newman (2015) suggested one of the green goals of this sector is enhancing its carbon management [22]. Therefore, both of these initiatives which are related to carbon emission are being mentioned in all three exisiting checklists included in the systematic review.

However, most of initiatives mentioned between checklist differ. Referring to table 2, it shows a total of 74 initiatives are being mentioned in only one of the existing checklists. This may be due to the fact that the existing checklists were developed on a different basis. A checklist developed by Noh an Ahn (2018) focuses on the aspects of architectural, services, materials, and programs. Differ with checklist developed by Werner (2013) which include the aspect of design and construction along with library's operations. Third checklist involved in the systematic review developed by Mulford and Himmel (2010) however was developed with intention to measure the current condition of an existing library. Hence, due to different aspects being taken into consideration in developing these checklists, most initiatives mentioned in these three existing checklists differ between each other.

\subsection{Assessment Checklist for Green Initiatives in Library's Facilities}

As stated in 2.1, the final phase of the systematic review involved coding the green initiatives based on themes. Hence, table 3 indicates the comparison between evaluation areas being mentioned in three existing checklists involved in this study.

Table 3 - Summary of comparison between evaluation areas mentioned in three of the existing checklists

\begin{tabular}{ccccc}
\hline No & Theme & $\begin{array}{c}\text { Noh and } \\
\text { Ahn } \\
\text { (2018) }\end{array}$ & $\begin{array}{c}\text { Werner } \\
\mathbf{( 2 0 1 3 )}\end{array}$ & $\begin{array}{c}\text { Mulford } \\
\text { and } \\
\text { Himmel } \\
\text { (2010) }\end{array}$ \\
\hline 1 & Energy & $\checkmark$ & $\checkmark$ & $\checkmark$ \\
\hline 2 & Indoor environment & $\checkmark$ & & $\checkmark$ \\
\hline 3 & Materials and resources & $\checkmark$ & & $\checkmark$ \\
\hline 4 & Water & $\checkmark$ & & \\
\hline 5 & Computerisation & $\checkmark$ & $\checkmark$ & \\
\hline 6 & Operations & $\checkmark$ & & \\
\hline 7 & Prevention of environmental pollution & $\checkmark$ & & \\
\hline 8 & Maintenance & $\checkmark$ & & \\
\hline 9 & Ecological environment & $\checkmark$ & & \\
\hline 10 & Library resources & $\checkmark$ & & \\
\hline 11 & Program and education & $\checkmark$ & & \\
\hline 12 & Employees & $\checkmark$ & & \\
\hline 13 & Traffic and land use & & \\
\hline 14 & Site location & & $\checkmark$ \\
\hline 15 & Project planning & & \\
\hline 16 & Tendering & & \\
\hline
\end{tabular}




\begin{tabular}{lcl}
\hline 17 & Construction & $\checkmark$ \\
\hline 18 & Structure & $\checkmark$ \\
\hline 19 & Façade & $\checkmark$ \\
\hline 20 & Building materials & $\checkmark$ \\
\hline 21 & Building climate & $\checkmark$ \\
\hline 22 & Light & $\checkmark$ \\
\hline 23 & Interior fittings & $\checkmark$ \\
\hline 24 & User services & $\checkmark$ \\
\hline 25 & Environmental management certificates & $\checkmark$ \\
\hline 26 & Green building certificates & $\checkmark$ \\
\hline 27 & Product certificates & $\checkmark$ \\
\hline 28 & Facilities management & $\checkmark$ \\
\hline 29 & Green office & $\checkmark$ \\
\hline 30 & Strategic goals & $\checkmark$ \\
\hline 31 & Marketing and public relation & \\
\hline 32 & Sustainable sites & $\checkmark$ \\
\hline 33 & Design & \\
\hline
\end{tabular}

As shown in Table 3, amongst the three existing checklists involved in the systematic review, a total of 33 evaluation areas were identified. From these 33 evaluation areas, one evaluation area is being mentioned in all three existing checklists, five are being mentioned in two of the existing checklists, and 27 are being mentioned in one existing checklist. From table 3, it indicates that evaluation areas may vary between checklists. Therefore, inductive coding was carried out in order to categorised those initiatives stated in table 2 into suitable themes.

Though only one evaluation area is similarly mentioned in all three existing checklists, some initiatives are being mentioned in multiple checklists but categorised under different evaluation areas. For instant, referring back to 3.2, six initiatives were identified having been mentioned in all three existing checklists involved in the systematic review. Those initiatives are: (1) Utilizing solar energy to generate electricity, (2) Incorporating rainwater harvesting, (3) Incorporating greywater system, (4) Enhancing intake of daylight for interior space, (5) Establishing connection to public transport, and (6) Using eco-friendly cleaning products. However, initiatives such as incorporating rainwater harvesting and greywater system are mentioned in checklists developed by Noh and Ahn (2018) and Mulford and Himmel (2010) under the evaluation area 'water.' However, this evaluation area is absence from a checklist developed by Werner (2013). Nevertheless, as mentioned in 3.2, the initiatives of incorporating rainwater harvesting and greywater system are included in all three existing checklists including the checklist developed by Werner (2013). As shown in the checklist by Werner (2013), these initiatives are allocated under the evaluation area 'energy, light.' In addition, the initiative 'enhancing intake of daylight for interior space' is also mentioned in all three existing checklists as mentioned in 3.2. However, the evaluation area under which this initiative is allocated differ between those checklists. Checklist developed by Noh and Ahn (2018) allocates this initiative under the evaluation area 'energy and prevention of environmental pollution.' Whereby, Werner (2013) allocates the similar initiative under the evaluation area 'energy and light' and checklist developed by Mulford and Himmel (2010) allocates this initiative under the evaluation area 'indoor environmental air quality.' Thus, indicating though similar initiatives may be mentioned in multiple existing checklists, the evaluation area in which these initiatives are categorised may differ. Additionally, this leads to a total of 27 evaluation areas being mentioned in only one existing checklist each.

Thereby, 104 initiatives mentioned in table 2 were grouped based on similar characteristics to develop themes in developing the checklist for this study. Themes developed for those initiatives are shown in table 4. In addition, apart from 104 initiatives mentioned in three existing checklists involved in the systematic review, an additional of three green initiatives can be implemented in library as suggested by Binks et al. (2014) are included. These initiatives involved: (1) Providing charging station for electric vehicle, (2) Using carpet tiles as floor finishes, and (3) Displaying signage in staffing areas to encourage environmentally friendly behaviour. Though these initiatives are not mentioned in checklists involved in the systematic review, Binks et al. (2014) suggested to enable library to operate more sustainably, these initiatives can be incorporated in library [3].

Table 4 - Final assessment checklist for green initiatives in library's facilities

\begin{tabular}{|c|c|}
\hline Theme & Initiatives \\
\hline \multirow{5}{*}{ Energy } & Utilized software solutions to optimize energy consumption \\
\hline & $\begin{array}{l}\text { Utilized energy-saving electrical appliance and energy-efficient hot water } \\
\text { production for kitchen }\end{array}$ \\
\hline & Provided solar energy for cooling or heating \\
\hline & Utilized hydrogen fuel cell for electricity \\
\hline & Utilized bio-energy for electricity \\
\hline
\end{tabular}


Utilized solar energy generation for electricity

Conducted an energy audit of the facility

Established agreed target for energy saving

Made energy-use visible

Tracked energy usage

Avoided major use of air-conditioning

Used influx and release of outside air for air-conditioning

Provided occupant-controlled lighting

Used steel halide lamp with low voltage

Installed lighting controlled by sensors

Used fluorescent light with high energy efficiency

Installed step switching and dimmer switches

Installed efficient lighting control panels

Used thin clients instead of PCs

Used high efficient printer

Recovered waste heat from refrigeration and air-conditioning systems to heat water

Installed electric flash heater

Displayed signage in staffing areas encouraging environmentally friendly

behaviour

Tracked water usage

Conducted water usage audit

Used water-efficient fixtures

Incorporated rainwater harvesting

Water $\quad$ Installed drain to collect rainwater

Installed facilities utilizing rainwater

Utilized rainwater for irrigation

Installed automatic irrigation facilities

Incorporated greywater system

Installed sewage purification system

Conducted solid-waste audit of the facility

Reused items that have useful life

Installed collection box for used batteries

Installed storage facilities for recycled waste

Recycled waste books

Recycled printer cartridges

Waste $\quad$ Recycled and donated e-waste

Recycled constrainers and packaging

Recycled lightbulb

Recycled library furniture

Provided alternatives to plastic bags

Used biodegradable or real plates and utensils

Composted spent vegetation

Provided manual and guidelines for effective operation and maintenance of

equipment and facility to manager of building

Operation \& $\quad$ Performed regular maintenance on all building systems

Maintenance Utilized building control system

Performed remote management

Complied to ISO 14000

Used materials with low diffusion rate of VOC

Installed indoor air purification system

Provided switchable sockets for PCs and printers

Fixtures \& $\quad$ Installed acoustic baffles

furnishing $\quad$ Installed revolving doors

Utilized certified eco-labelling products

Installed heat recovery ventilation system in ceiling

Used renewable, reusable or recyclable fixtures and furnishing

Reused shelved of existing buildings 
Installed blinds at windows

Installed low-lying windows

Installed windows with glazing quality that supports thermal insulation

Utilized computer control system to enable adjustment of glass windows

Used facilities to enable influx of sunlight in roof and ceiling

Utilized facilities made up of translucent materials to allow light transmission

Used materials obtained from library land site for indoor facilities

Installed automatic air-circulation system

Purchased fixtures and furnishing locally

Evaluated certification of displaying carbon dioxide score for used materials

Used carpet tiles as floor finishes

Used drought-resistant plants

Linked indoor library with an ecological park

Incorporated green roof

Landscape Incorporated green wall

Provided green outdoor environment and landscaping

Utilized trees and sunlight

Irrigated site landscape

Designed effective space arrangement by considering user movement flow

Provided rest space

Space $\quad$ Provided flexible use of library spaces

Provided differentiation of climate concept according to library function

Divided area types according to ecological values

Utilized extensive resource saving compact storage

Performed night cooling

Ventilated library before opening

Provided natural ventilation

Provided interior space with access to outside views

Indoor Avoided artificial humidification

environment Provided individual climate control in workspaces

Provided interior space with access to daylight

Influx outside air through carbon dioxide monitoring

Complied to non-smoking policy

Conducted environmental quality audit

Re-used air from print or copy rooms and air-conditioning

Provided bicycle shed

Established connections to public transport

Allowed forms to be completed and submitted electronically

Transport Utilized electronic or digital communication

Provided alternative commuting options for staff

Reduced emission of carbon dioxide in transportation by using local materials

Provided electric vehicle charging station

Used eco-friendly cleaning products

Ensured economic usage of cleaning materials

Housekeeping Isolated chemicals and storage in ventilated room

Avoided the use of pesticides and chemical fertilizer

Controlled noise during cleaning routines

Overall, 10 themes were developed through inductive coding to categorise those 107 initiatives identified. Those themes include: (1) Energy, (2) Water, (3) Waste, (4) Operation and maintenance, (5) Fixtures and furnishing, (6) Landscape, (7) Space, (8) Indoor environment, (9) Transport, and (10) Housekeeping. Hence, result of the first objective also serves as this study's own checklist which fulfilled the second objective of this study.

\section{Conclusion}

In conclusion, this study found that previous literatures focusing on green initiatives in library are limited in which only three previous literatures with green assessment checklist for library were found. This is indeed agreed by Hauke (2015) which claimed there is insufficient certification and rating system designed specifically for green library [8]. 
Hence, due to lack of rating system with regards to green library, this may lead to difficulty for an existing library approaching green initiatives.

Nonetheless, from systematic review carried out, this study able to identify 107 initiatives can be taken by existing library situated in Malaysia to environmentally improve its facilities. These initiatives were derived from an existing checklist developed by Noh and Ahn (2018), Werner (2013), and Mulford and Himmel (2010). Additionally, these initiatives are divided into 10 main themes which include: (1) Energy, (2) Water, (3) Waste, (4) Operation and maintenance, (5) Fixtures and furnishing, (6) Landscape, (7) Space, (8) Indoor Environment, (9) Transportation, and (10) Housekeeping.

With regards to future research, since the assessment checklist developed in this study is formulated by referring to three existing checklists by Noh and Ahn (2018), Werner (2013), and Mulford and Himmel (2010), future research can be carried to add more ideas regarding green initiatives that can be taken in library. In addition, in conducting the literature review, this study only focuses on existing literatures that specifically measure green initiatives in library which is found to be limited. Therefore, existing literatures which measure green initiatives in other types of building may also be included in future study if the initiatives are found to be applicable in library.

Finally, the assessment checklist formulated in this study does not include specific evaluation guidelines for each initiative and the checklist formulated does not include a rating system to rate library based on green initiatives implemented. Thus, a future study developing specific evaluation guidelines for each initiative and an overall rating system for the checklist formulated in this study can be carried out.

\section{Acknowledgement}

The author would like to thank Faculty of Architecture, Planning and Surveying, Universiti Teknologi MARA for supporting this research work.

\section{References}

[1] Amin, N. N. B., \& Shoid, M. S. M. (2017). Conceptualizing User Satisfaction Toward a Library Quality at Malaysia Nuclear Agency Library. International Journal of Academic Research in Progressive Education and Development, 6(3), 247-252.

[2] Babare, A. A., \& Aute, G. P. (2018). Green Library: An overview. An International Peer Reviewed Bilingual EJournal of Library and Information Science, 218-221.

[3] Binks, L., Braithwaite, E., Hogarth, L., Logan, A., \& Wilson, S. (2014). Tomorrow's Green Public Library. The Australian Library Journal, 63(4), 301-312.

[4] Burn, D. (2014). The Grove Library as an Example: A green library in terms of ongoing community engagement, community expectations, information provision and sharing, and partnerships. IFLA 2014.

[5] Cardoso, N. B., \& Machado, E. C. (2015). Sustainable and Green Libraries in Brazil: Guidelines for local governments. IFLA WLIC 2015.

[6] Gupta, E., Natarajan, R., Gulati, A., \& Batcha, M. S. (2018). Implementation of Green Library Techniiques at C.S.J.M. University Library: A viability study. International Journal of Research in Engineering, IT and Social Sciences, 8(6), 46-50.

[7] Hauke, P., Werner, K. U., \& Latimer, K. (2013). The Green Library. IFLA Publications, 161.

[8] Hauke, P. (2015). How to Become/How to Identify a Green Library? Standards for certification. IFLA WLIC 2015.

[9] Hauke, P. (2019). Green Libraries Towards Green Sustainable Development. IFLA WLIC 2019 Athens.

[10] International Federation of Library Associations and Institutions. (2016). IFLA Green Library Award 2016 Winners Announced.

[11] International Federation of Library Associations and Institutions. (2019). IFLA Green Library Award.

[12] Jankowska, M. A., \& Marcum, J. W. (2010). Sustainability Challenge for Academic Libraries: Planning for the future. College \& Research Libraries, 71(2), 160-170.

[13] Leedy, P. D., \& Ormrod, J. E. (2015). Practical Research (Eleventh E). Pearson Education Limited.

[14] Library. (n.d.). In Merriam-Webster.com dictionary. Retrieved from https://www.merriamwebster.com/dictionary/library

[15] Malode, M. A. V. (2014). Green Library: An overview. International Multidisciplinary E-Research Journal, 1(4), $14-17$.

[16] McElrath, E., \& Sutherland, S. (2015). Environmental Sustainability and Libraries. International Journal of Humanities and Social Science, 5(12), 13-23.

[17] Meher, P., \& Parabhoi, L. (2017). Green Library: An overview, issues with special reference to Indian libraries. International Journal of Digital Library Services, 7(2), 62-69.

[18] More, T. D. (2016). Implementing Green Technology Practices and Culture in the Library. International Peer Reviewed Bilingual E-Journal of Library and Information Science, 3(3), 106-112. 
[19] Mulford, S. M., \& Himmel, N. A. (2010). How Green is My Library? Santa Barbara, California: Greenwood Publishing Group.

[20] Munawaroh, \& Bestari, M. P. (2018). The Initiation of Green Libraries: The case of STIE Perbanas Surabaya's Library. Jurnal Ilmu Informasi, Perpustakaan, Dan Kersipa, 20(1), 19-22.

[21] National Library of Malaysia. (2018). 2017 Annual Report of National Library of Malaysia.

[22] Newton, P., \& Newman, P. (2015). Critical Connections: The role of the built environment sector in delivering green cities and a green economy. Sustainability, 7, 9417-9443.

[23] Nikam, S. S. (2017). Green Library: An emerging concept. Library and Information Science, 4(6), $190-198$.

[24] Noh, Y., \& Ahn, I. J. (2018). Evaluation Indicators for Green Libraries and Library Eco-friendliness. International Journal of Knowledge Content Development \& Technology, 8(1), 51-77.

[25] Patil, S. S. (2018). Green Library Initiatives: An overview. International Conference on Internet of Things and Current Trends in Libraries, 109-116.

[26] Qutab, S., Ali, Z. F., \& Ulah, F. S. (2016). Environmentally Sustainable Library Buildings: Opportunities and challenges for Asian countries. IFLA WLIC 2016.

[27] Sustainable Library. (n.d.). In Online Dictionary for Library and Information Science. Retrieved from https://products.abc-clio.com/ODLIS/odlis_s.aspx\#sustainablelib

[28] Tender for Sabah's First Green Library to be Called Soon. (2012, May 23). Borneo Post Online. Retrieved from https://www.theborneopost.com/2012/05/23/tender-for-sabahs-first-green-library-to-be-called-soon/

[29] Werner, K. U. (2013). Sustainable Buildings, Equipment and Management: A checklist. IFLA Publications, 161, $1-10$.

[30] Wong, L. J. W. (2016). More than just a Green Building: Developing green strategies at the Chinese University of Hong Kong Library. Library Management, 37(6/7).

[31] World Commission on Environment and Development. (1987). Brundtland Report.

[32] Yusof, Z. B., \& Jamaludin, M. (2015). Green Practices of Small Island Chalet Operators in East Peninsular Malaysia. Procedia - Social and Behavioral Sciences, 202, 340-350. 